KONSTRUKTIVISME, Vol. 10, No. 1, Januari 2018

p-ISSN: 1979-9438; e-ISSN: 2442-2355

FKIP Universitas Islam Balitar, Blitar

Http://konstruktivisme.unisbablitar.ejournal.web.id; Email: konunisba@gmail.com

\title{
ANALISIS GAYA BELAJAR MAHASISWA DAN HUBUNGANNYA DENGAN \\ HASIL BELAJAR KIMIA DASAR MAHASISWA PROGRAM STUDI ILMU \\ TERNAK FAKULTAS PETERNAKAN UNIVERSITAS ISLAM BALITAR SEMESTER GANJIL TAHUN AKADEMIK 2016-2017
}

\author{
Devita Sulistiana \\ Program Studi Pendidikan Biologi \\ Fakultas Keguruan dan IImu Pendidikan \\ Universitas Islam Balitar Blitar \\ JI. Majapahit No. 4 Blitar \\ devitasulistiana17@gmail.com
}

\section{ABSTRAK :}

Penelitian ini bertujuan untuk mengetahui hubungan gaya belajar mahasiswa dan hasil belajar mata kuliah kimia dasar mahasiswa program studi ilmu ternak Fakultas peternakan Universitas Islam Balitar Semester ganjil tahun akademik 2016-2017. Jenis penelitiannya adalah penelitian deskriptif kualitatif. Data dalam penelitian adalah data kualitatif dan kuantitatif. Data kuantitatif didapat dari angket, observasi dan dokumentasi hasil belajar mahasiswa, sedangkan data kualitatif didapat dari wawancara. Sampel pada penelitian ini adalah mahasiswa program studi ilmu ternak Fakultas peternakan Universitas Islam Balitar Semester ganjil tahun akademik 2016-2017 yang berjumlah 44 orang. Teknik analisis data yang digunakan dalam penelitian ini adalah analisis sederhana untuk mencari hubungan antara gaya belajar dengan hasil belajar. Hasil penelitian diketahui keseluruhan terlihat bahwa gaya belajar mahasiswa program studi ilmu ternak Fakultas peternakan Universitas Islam Balitar Semester ganjil tahun akademik 2016-2017adalah auditorial 22 orang $(44 \%)$, visual 16 orang $(32 \%)$, kinestisia 3 orang $(6 \%)$, gaya belajar campuran 4 orang $(6 \%)$, gaya belajar visual dan kinestisia 4 orang $(8 \%)$ dan gaya belajar auditorial dan visual 3 orang (4\%). Mahasiswa dengan gaya belajar kinestetik dapat menguasai mata kuliah kimia dasar dengan persentase ketuntasan $100 \%$, sementara mahasiswa dengan gaya belajar auditorial $86 \%$, dan visual $81 \%$.

Kata kunci: gaya belajar, hasil belajar, kimia dasar 
Devita Sulistiana. 2018. Analisis Gaya Belajar Mahasiswa Dan Hubungannya Dengan Hasil Belajar Kimia Dasar Mahasiswa Program Studi Ilmu Ternak Fakultas Peternakan Universitas Islam Balitar Semester Ganjil Tahun Akademik 2016-2017.

Universitas Islam Balitar.

Konstruktivisme, 10 (1): 84-97

\section{ABSTRACT :}

The aim of this research was to know the relationship between the student's style learning and learning achievement of student's basic chemistry in the animal science study program, faculty of animal husbandry at Islamic University of Balitar in the ood semester 2016-2017 academic year. This research was descriptive qualitative research. The research data were qualitative and quantitative. Quantitative data was obtained from questioner and the student's learning results documentation. While the qualitative data obtained from interview. The sample of this research were the students of animal science study program, faculty of animal husbandry at Islamic University of Balitar in the ood semester 2016-2017 academic year which amounted 44 people. The data analysis technique that used in this research was simple analysis to find the relationship between the student's learning style and learning achievement. The result of the research revealed that the learning style of students' animal science study program, faculty of animal husbandry at Islamic University of Balitar in the ood semester 2016-2017 academic year are auditory were 22 people (44\%), visual 16 people (32\%), kinesthetic 3 people $(6 \%)$, mixed learning style 4 people $(6 \%)$, visual and kinesthetic learning styles 4 people (8\%), auditory and visual learning styles $3(4 \%)$. The stduents with kinesthetic learning styles can mastering the basic chemistry course with a percentage $100 \%$ completeness, while students with auditory learning styles were $86 \%$, and visuals were $81 \%$.

Keywords: Learning Style, Learning Achievement, Basic Chemistry.

\section{PENDAHULUAN}

Gaya belajar adalah cara yang konsisten yang dilakukan oleh seorang murid dalam menangkap stimulus atau informasi, cara mengingat, berpikir, dan memecahkan soal. Tidak semua orang mengikuti cara yang sama. Masingmasing menunjukkan perbedaan, namun para peneliti dapat menggolonggolongkannya. Gaya belajar ini berkaitan erat dengan pribadi seseorang, yang tentu dipengaruhi oleh pendidikan dan riwayat perkembangannya (Nasution, 2010:94). Bagaimana sebuah informasi dapat diterima dengan baik oleh anak didiknya. Jadi antara gaya mengajar dosen dan gaya belajar anak didik adalah dua hal yang sangat berkaitan, saling mendukung satu dengan yang lain, dan 
Devita Sulistiana. 2018. Analisis Gaya Belajar Mahasiswa Dan Hubungannya Dengan Hasil Belajar Kimia Dasar Mahasiswa Program Studi Ilmu Ternak Fakultas Peternakan Universitas Islam Balitar Semester Ganjil Tahun Akademik 2016-2017.

Universitas Islam Balitar.

Konstruktivisme, 10 (1): 84-97

sangat menentukan keberhasilan suatu proses belajar mengajar. Gaya belajar ini merupakan salah satu aspek yang perlu mendapat perhatian.

Gaya belajar merupakan cara termudah yang dimiliki oleh individu dalam menyerap, mengatur dan mengolah informasi yang diterima. Gaya belajar yang sesuai adalah kunci keberhasilan seseorang dalam belajar. Oleh karena itu, dalam kegiatan belajar, mahasiswa sangat perlu dibantu dan diarahkan untuk mengenali gaya belajar yang sesuai dengan dirinya sehingga tujuan pembelajaran dapat dicapai secara efektif. Sebagai seorang pendidik dosen harus mampu mengakomodir semua gaya belajar mahasiswa. Menurut Fleming dan Mills, "gaya belajar merupakan kecenderungan siswa untuk mengadaptasi strategi tertentu dalam belajarnya sebagai bentuk tanggung jawabnya untuk mendapatkan satu pendekatan belajar yang sesuai dengan tuntutan belajar di kelas/sekolah maupun tuntutan dari mata pelajaran.

Menurut DePorter dan Hernacki (1999), gaya belajar adalah kombinasi dari menyerap, mengatur, dan mengolah informasi. Secara umum, gaya belajar dikelompokkan berdasarkan kemudahan dalam menyerap informasi (perceptual modality), cara memproses informasi (information processing), dan karakteristik dasar kepribadian (personality pattern). Pengelompokan berdasarkan perceptual modality didasarkan pada reaksi individu terhadap lingkungan fisik dan cara individu menyerap data secara lebih efisien. Pengelompokan berdasarkan information processing didasarkan pada cara individu merasa, memikirkan, memecahkan masalah, dan mengingat informasi. Sedangkan pengelompokan berdasarkan personality pattern didasarkan pada perhatian, emosi, dan nilai-nilai yang dimiliki oleh individu. DePorter dan Hernacki (1999) mengemukakan tiga jenis gaya belajar berdasarkan modalitas yang digunakan individu dalam memproses informasi (perceptual modality). Ketiga gaya belajar tersebut adalah gaya belajar visual, auditorial, dan kinestetik.

Orang yang memiliki gaya belajar visual, belajar dengan menitikberatkan ketajaman penglihatan. Artinya, bukti-bukti konkret harus diperlihatkan terlebih dahulu agar mereka paham. Orang yang memiliki gaya belajar auditory, belajar dengan mengandalkan pendengaran untuk bisa memahami sekaligus mengingatnya. Karakteristik model belajar ini benar-benar menempatkan pendengaran sebagai alat utama untuk menyerap informasi atau pengetahuan. Artinya, untuk bisa mengingat dan memahami informasi tertentu, yang bersangkutan haruslah mendengarnya lebih dulu. Orang yang memiliki gaya belajar kinestetik, mengharuskan individu yang bersangkutan menyentuh 
Devita Sulistiana. 2018. Analisis Gaya Belajar Mahasiswa Dan Hubungannya Dengan Hasil Belajar Kimia Dasar Mahasiswa Program Studi Ilmu Ternak Fakultas Peternakan Universitas Islam Balitar Semester Ganjil Tahun Akademik 2016-2017. Universitas Islam Balitar.

Konstruktivisme, 10 (1): 84-97

sesuatu yang memberikan informasi tertentu agar ia bisa mengingatnya.

Menurut Gunawan (Nurochma, 2012:6) keberhasilan pembelajaran selain dipengaruhi oleh metode yang digunakan oleh dosen juga dipengaruhi oleh faktor lain, salah satunya adalah gaya belajar. Gaya belajar adalah cara yang lebih disukai dalam melakukan kegiatan berpikir memproses dan mengerti suatu informasi. Hakikat ilmu kimia tidak hanya berupa teori, hafalan dan pemahaman akan konsep saja, tetapi juga berupa proses penerapan dan bahkan penemuan, maka dalam pembelajarannya harus melibatkan mahamahasiswa secara aktif untuk berinteraksi dengan objek konkret. Selain itu mahasiswa juga harus terlibat secara aktif dalam mengamati, mengoperasikan alat, berlatih menggunakan objek konkret, meramalkan gejala fisis yang terjadi, menerapkan konsep, merencanakan penelitian, berkomunikasi secara ilmiah dan mengajukan pertanyaan.

Dalam proses pembelajaran yang terjadi tentunya hasil belajar merupakan hasil akhir yang akan dicapai oleh mahasiswa. Pencapaian hasil belajar ini tentunya tidak lepas dari peranan dosen sebagai seorang pendidik dan pengajar. Dari hasil pengamatan sebelum melakukan penelitian, peneliti menemukan bahwa beberapa masalah yang muncul di Program Studi IImu Ternak Fakultas Peternakan UNISBA Blitar bahwa kemampuan seseorang untuk memahami dan menyerap pelajaran berbeda tingkatnya. Ada yang cepat dalam menyerap pelajaran, sedang dan ada pula yang sangat lambat dalam menyerap pelajaran yang telah diajarkan oleh dosen. Karenanya, mereka sering kali harus menempuh cara yang berbeda untuk bisa memahami informasi atau pelajaran yang sama. Mahasiswa lebih menyukai dosen mengajar dengan cara menuliskan segalanya di papan tulis. Dengan begitu mereka bisa membaca untuk kemudian mencoba memahaminya. Tapi, sebagian mahasiswa lain lebih suka dosen mengajar dengan menyampaikannya secara lisan dan mereka mendengarkan untuk bisa memahaminya. Sementara itu, ada mahasiswa yang lebih suka membentuk kelompok kecil untuk mendiskusikan pertanyaan yang menyangkut pelajaran tersebut cara lain yang juga kerap disukai banyak mahasiswa adalah model belajar yang menempatkan dosen tak ubahnya seorang penceramah.

Dosen diharapkan bercerita panjang lebar tentang beragam teori dengan segudang ilustrasinya, sementara para mahasiswa mendengarkan sambil menggambarkan isi ceramah itu dalam bentuk yang hanya mereka pahami sendiri. Oleh sebab itu peneliti ingin mengetahui tentang gaya belajar yang digunakan mahasiswa Program Studi IImu Ternak Fakultas Peternakan UNISBA 
Devita Sulistiana. 2018. Analisis Gaya Belajar Mahasiswa Dan Hubungannya Dengan Hasil Belajar Kimia Dasar Mahasiswa Program Studi Ilmu Ternak Fakultas Peternakan Universitas Islam Balitar Semester Ganjil Tahun Akademik 2016-2017. Universitas Islam Balitar.

Konstruktivisme, 10 (1): 84-97

Blitar dan hubungannya dengan hasil belajar yang diperoleh. Hasil penelityian yang dilakukan Fajar Hendro $U$, dkk yang berjudul Deskripsi Komunikasi Matematika Berdasarkan Tingkat Berfikir Teori Van Hiele Pada Mata Kuliah Geometri Ditinjau dari Gaya Belajar Mahasiswa Program Studi Pendidikan Matematika STKIP PGRI Tulungagung, diketahui bahwa ditinjau dari gaya belajar, tingkat kemampuan komunikasi matematika mahasiswa berdasarkan teori van hiele ditinjau dari gaya belajar kinestatik lebih banyak masuk level 3 yang artinya ketika mahasiswa menciptakan definisi yang bermakna dan memberi argumen informal untuk membenarkan penalaran mereka, peran dan signifikansi dari deduksi formal tidak dipahami. Penelitian lain oleh Arylien L.B, dkk mendapatkan hasil bahwa gaya belajar visual, auditorial, dan kinestetik secara simultab maupun secara terpisah dapat mempengaruhi prestasi belajar siswa pada Jurusan Bangunan SMK Negeri 5 Kupang Tahun Ajaran 2013/2014.

Berdasarkan latar belakang masalah inilah, membuat peneliti tertarik untuk melakukan pembahasan dengan tema gaya belajar, dengan judul penelitian: Analisis Gaya Belajar Mahasiswa dan Hubungannya Dengan Hasil Belajar Kimia Dasar mahasiswa IImu Ternak Fakultas Peternakan Universitas Islam Balitar Semester Ganjil Tahun Akademik 2016-2017.

\section{METODE PENELITIAN}

\section{Waktu dan Tempat Penelitian}

Penelitian ini dilakukan pada mahasiswa Program Studi IImu Ternak Fakultas Peternakan Universitas Islam Balitar Semester Ganjil Tahun Akademik 2016-2017.

\section{Rancangan Penelitian}

Jenis penelitian adalah penelitian deskriptif (descriptivecorelasional) Penelitian deskriptif merupakan metode penelitian yang berusaha menggambarkan dan menginterpretasi objek sesuai dengan apa adanya. Penelitian deskriptif ini juga disebut penelitian noneksperimen, karena dalam penelitian ini peneliti tidak melakukan kontrol dan manipulasi variabel penelitian (Sukardi, 2008:157). Penelitian deskriptif bertujuan untuk menggambarkan secara sistematis fakta dan karakteristik objek atau subyek yang diteliti sesuai dengan apa adanya dan korelasional bertujuan untuk mengetahui hubungan antara variabel gaya belajar mahasiswa $(X)$ dengan hasil belajar kimia dasar $(Y)$. Dalam hal ini peneliti berusaha memberikan gambaran satu keadaan dan 
Devita Sulistiana. 2018. Analisis Gaya Belajar Mahasiswa Dan Hubungannya Dengan Hasil Belajar Kimia Dasar Mahasiswa Program Studi IImu Ternak Fakultas Peternakan Universitas Islam Balitar Semester Ganjil Tahun Akademik 2016-2017.

Universitas Islam Balitar.

Konstruktivisme, 10 (1): 84-97

fenomena yang terjadi di lapangan baik yang diteliti maupun yang diamati, mengenai gaya belajar mahasiswa dan hubungannya dengan hasil belajar Kimia Dasar Mahamahasiswa IImu Ternak Fakultas Peternakan Universitas Islam Balitar Semester Ganjil Tahun Akademik 2016-2017.

\section{HASIL DAN BAHASAN}

\section{Hasil}

Berdasarkan observasi yang telah dilakukan didapat hasil bahwa gaya belajar mahasiswa Program Studi IImu Ternak Fakultas Peternakan Universitas Islam Balitar Semester Ganjil Tahun Akademik 2016-2017, hasilnya adalah sebagai berikut:

Tabel 1. Distribusi hasil observasi gaya belajar Mahasiswa Program Studi IImu Ternak Fakultas Peternakan Universitas Islam Balitar Semester Ganjil Tahun Akademik 2016-2017

\begin{tabular}{|c|c|c|c|}
\hline No. & Pernyataan & $\begin{array}{c}\text { Persentase } \\
(\%)\end{array}$ & Kategori \\
\hline 1 & Mendengarkan ceramah dari dosen & 89 & Sangat tinggi \\
\hline 2 & $\begin{array}{l}\text { Mendengarkan pendapat, informasi dan } \\
\text { saran dari teman }\end{array}$ & 72 & Tinggi \\
\hline 3 & $\begin{array}{l}\text { Mengerjakan tugas dengan } \\
\text { mendengarkan petunjuk terlebih dahulu }\end{array}$ & 92 & Sangat tinggi \\
\hline 4 & $\begin{array}{l}\text { Belajar diselingi dengan } \\
\text { musik/cerita }\end{array}$ & 56 & Cukup \\
\hline 5 & $\begin{array}{l}\text { Belajar dalam situasi kondisi yang } \\
\text { tenang }\end{array}$ & 60 & Cukup \\
\hline 6 & Mengerjakan tugas, tes secara lisan & 56 & Cukup \\
\hline 7 & $\begin{array}{l}\text { Mengerjakan tugas dengan melihat } \\
\text { instruksi, contoh terlebih dahulu }\end{array}$ & 88 & Sangat tinggi \\
\hline 8 & $\begin{array}{l}\text { Mengerjakan tugas dengan melihat } \\
\text { tugas } \\
\text { teman }\end{array}$ & 62 & Tinggi \\
\hline 9 & Mengerjakan tugas, tes secara tertulis & 84 & Sangat tinggi \\
\hline 10 & Mengamati, memahami media & 90 & Sangat tinggi \\
\hline 11 & Menggunakan media & 66 & Tinggi \\
\hline 12 & Melihat media & 68 & Tinggi \\
\hline 13 & Keterlibatan fisik dalam belajar & 66 & Tinggi \\
\hline
\end{tabular}


Devita Sulistiana. 2018. Analisis Gaya Belajar Mahasiswa Dan Hubungannya Dengan Hasil Belajar Kimia Dasar Mahasiswa Program Studi Ilmu Ternak Fakultas Peternakan Universitas Islam Balitar Semester Ganjil Tahun Akademik 2016-2017. Universitas Islam Balitar.

Konstruktivisme, 10 (1): 84-97

\begin{tabular}{llll}
14 & Belajar melalui praktek & 78 & Sangat tinggi \\
15 & Belajar sambil berjalan/menonton/cerita & 62 & Tinggi \\
\hline
\end{tabular}

Dari Tabel 1 di atas dapat diketahui bahwa gaya belajar mahasiswa yang sangat tinggi adalah mendengarkan ceramah dari dosen (89\%), mengerjakan tugas dengan mendengarkan petunjuk terlebih dahulu (92\%) dikategorikan gaya belajar auditorial. Gaya belajar mahasiswa yang dikategorikan tinggi adalah mendengarkan pendapat, informasi dan saran dari teman $(72 \%)$ merupakan gaya belajar auditorial. Gaya belajar yang dikategorikan gaya belajar auditorial juga dengan persentase cukup tinggi adalah belajar diselingi dengan musik/cerita (56\%), belajar dalam situasi kondisi yang tenang $(60 \%)$.

Gaya belajar yang dikategorikan gaya belajar visual dengan persentase sangat tinggi (88\%) adalah mengerjakan tugas dengan melihat instruksi, contoh terlebih dahulu dan mengamati, dan memahami media (90\%). Dengan persentase tinggi $(62 \%)$ dikategorikan gaya belajar visual juga adalah dalam mengerjakan tugas mahasiswa lebih suka melihat tugas teman, melihat media (68\%). Selanjutnya gaya belajar sinestesia dengan persentase sangat tinggi adalah belajar melalui praktek $(78 \%)$, mengerjakan tugas, tes secara tertulis $(62 \%)$, persentase tinggi adalah menggunakan media (66\%), keterlibatan fisik dalam belajar $(66 \%)$, belajar sambil berjalan/menonton/cerita $(62 \%)$ dan mengerjakan tugas, tes secara lisan(54\%).

Berdasarkan angket penelitian yang telah dilakukan pada seluruh indikator gaya belajar mahasiswa pada pembelajaran kimia dasar Mahasiswa Program Studi IImu Ternak Fakultas Peternakan Universitas Islam Balitar Semester Ganjil Tahun Akademik 2016-2017diperoleh persentase sebagai berikut:

Tabel 2. Distribusi hasil persentase angket secara keseluruhan dari indikator gaya belajar Mahasiswa Program Studi IImu Ternak Fakultas Peternakan Universitas Islam Balitar Semester Ganjil Tahun Akademik 2016-2017

\begin{tabular}{llll}
\hline No. & Indikator & Frekuensi & Presentase \\
\hline & & 90 &
\end{tabular}


Devita Sulistiana. 2018. Analisis Gaya Belajar Mahasiswa Dan Hubungannya Dengan Hasil Belajar Kimia Dasar Mahasiswa Program Studi Ilmu Ternak Fakultas Peternakan Universitas Islam Balitar Semester Ganjil Tahun Akademik 2016-2017.

Universitas Islam Balitar.

Konstruktivisme, 10 (1): 84-97

\begin{tabular}{llcc}
\hline & & & $(\%)$ \\
\hline 1 & Gaya belajar auditor & 22 & 48 \\
2 & Gaya belajar visual & 16 & 35 \\
3 & Gaya belajar kinestetik & 6 & 14 \\
\hline & & 44 & 100 \\
\hline
\end{tabular}

Berdasarkan Tabel 2. di atas dapat dijelaskan bahwa gaya belajar auditorial yang dimiliki mahasiswa ada 22 orang $(48 \%)$, gaya belajar visual ada 16 orang (35\%), dan gaya belajar kinestetik 6 orang (14\%). Distribusi hasil persentase angket secara keseluruhan dari indikator gaya belajar mahasiswa pada pembelajaran biologi di kelas XI MIA di SMA Negeri I Kademangan indikator dapat divisualisasikan dalam bentuk grafik sebagai berikut:

\section{Persentase Gaya Belajar}

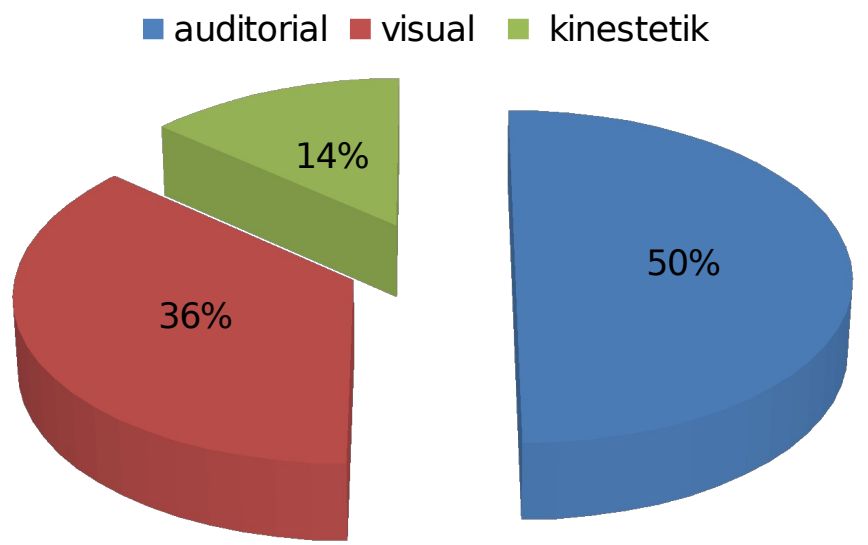

Gambar 1. Distribusi hasil persentase angket secara keseluruhan dari indikator gaya belajar Mahasiswa Program Studi IImu Ternak Fakultas Peternakan Universitas Islam Balitar Semester Ganjil Tahun Akademik 2016-2017

Berdasarkan hasil belajar matakuliah kimia dasar semester ganjil tahun akademik 2016-2017 dengan nilai KKM 70 diperoleh data sebagai berikut:

Tabel 3. Distribusi hasil persentase ketuntasan belajar matakuliah kimia dasar Mahasiswa Program Studi IImu Ternak Fakultas Peternakan 
Devita Sulistiana. 2018. Analisis Gaya Belajar Mahasiswa Dan Hubungannya Dengan Hasil Belajar Kimia Dasar Mahasiswa Program Studi IImu Ternak Fakultas Peternakan Universitas Islam Balitar Semester Ganjil Tahun Akademik 2016-2017.

Universitas Islam Balitar.

Konstruktivisme, 10 (1): 84-97

Universitas Islam Balitar Semester Ganjil Tahun Akademik 20162017

\begin{tabular}{ccc}
\hline Ketuntasan belajar & Jumlah & Persentase \\
\hline Tuntas & 38 & 86 \\
Tidak Tuntas & 6 & 14 \\
\hline Total & 44 & 100 \\
\hline
\end{tabular}

Sementara itu, hasil belajar matakuliah kimia dasar jika didasarkan pada gaya belajar diperoleh data sebagai berikut:

Tabel 4. Distribusi hasil ketuntasan belajar matakuliah kimia dasar berdasarkan gaya belajar Mahasiswa Program Studi IImu Ternak Fakultas Peternakan Universitas Islam Balitar Semester Ganjil Tahun Akademik 2016-2017

\begin{tabular}{cccc}
\hline $\begin{array}{c}\text { Ketuntasan } \\
\text { belajar }\end{array}$ & $\begin{array}{c}\text { Gaya Belajar } \\
\text { Auditori }\end{array}$ & $\begin{array}{c}\text { Gaya Belajar } \\
\text { Visual }\end{array}$ & $\begin{array}{c}\text { Gaya Belajar } \\
\text { Kinestetik }\end{array}$ \\
\hline Tuntas & 19 & 13 & 6 \\
Tidak Tuntas & 3 & 3 & 0 \\
\hline Total & 22 & 16 & 6 \\
\hline
\end{tabular}

Berdasarkan Tabel 4 di atas maka persentase hasil ketuntasan belajar matakuliah kimia dasar berdasarkan gaya belajar Mahasiswa Program Studi IImu Ternak Fakultas Peternakan Universitas Islam Balitar Semester Ganjil Tahun Akademik 2016-2017 dapat digambarkan sebagai berikut: 
Devita Sulistiana. 2018. Analisis Gaya Belajar Mahasiswa Dan Hubungannya Dengan Hasil Belajar Kimia Dasar Mahasiswa Program Studi Ilmu Ternak Fakultas Peternakan Universitas Islam Balitar Semester Ganjil Tahun Akademik 2016-2017.

Universitas Islam Balitar.

Konstruktivisme, 10 (1): 84-97

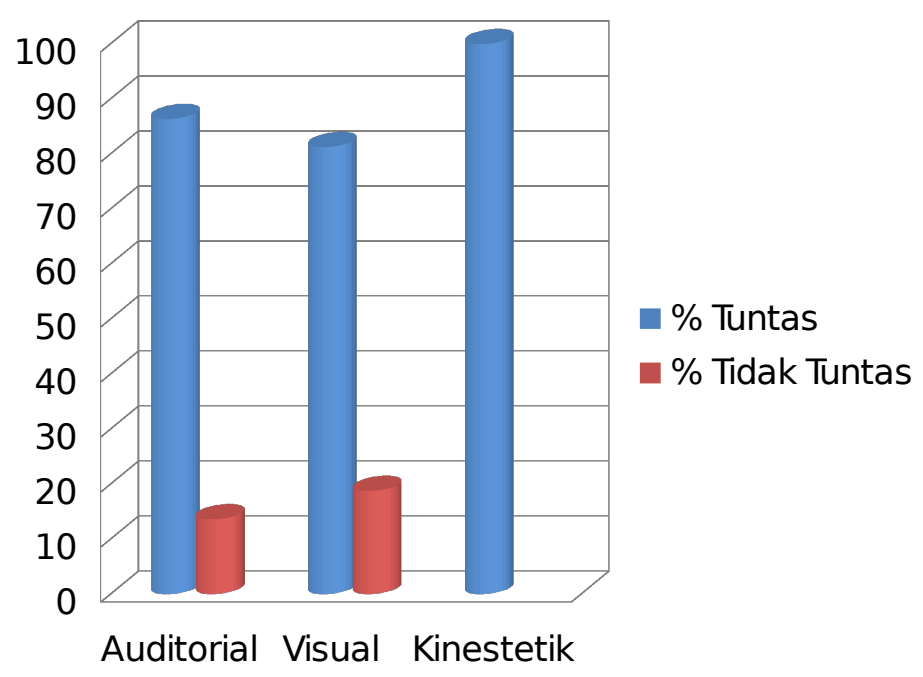

Gambar 2. Persentase ketuntasan belajar berdasarkan gaya belajar matakulian kimia dasar Mahasiswa Program Studi Ilmu Ternak Fakultas Peternakan Universitas Islam Balitar Semester Ganjil Tahun Akademik 2016-2017

\section{Bahasan}

Berdasarkan hasil penelitian ini diketahui bahwa mahasiswa program studi ilmu ternak Fakultas Peternakan UNISBA Blitar cenderung memiliki gaya belajar auditorial $(50 \%)$ dan visual (36\%). Hal ini menunjukkan bahwa mahasiswa cenderung menyukai belajar dengan mendengarkan dari orang lain, semisal ceramah. Mahasiswa mudah belajar, mudah menangkap stimuls atau rangsangan melalui indra pendenganrannya. Anak-anak dengan tipe seperti ini mudah mempelajari bahan-bahan yang disajikan dalam bentuk suara (ceramah), dan kata-kata (diskusi) atau dengan media audio lainnya (Subini, 2012). 36\% Mahasiswa memiliki gaya belajar visual yang menunjukkan bahwa mahasiswa lebih menguasai pembelajaran dengan menggunakan indra penglihatan. Mahasiswa dengan tipe seperti ini senang mengikuti ilustrasi, mengamati gambar, dan meninjau kejadian langsung. Gaya belajar visual adalah gaya belajar dengan cara melihat sehingga mata sangat memegang peranan penting. Gaya belajar secara visual dilakukan seseorang untuk memperolah informasi seperti melihat gambar, giagram, peta, poster, grafik, dan sebagainya. Bisa juga dengan melihat data teks seperti tulisan dan huruf (Subini, 2012). Sementara selebihnya, 14\% memiliki gaya belajar kinestetik. 
Devita Sulistiana. 2018. Analisis Gaya Belajar Mahasiswa Dan Hubungannya Dengan Hasil Belajar Kimia Dasar Mahasiswa Program Studi Ilmu Ternak Fakultas Peternakan Universitas Islam Balitar Semester Ganjil Tahun Akademik 2016-2017. Universitas Islam Balitar.

Konstruktivisme, 10 (1): 84-97

Berdasarkan data hasil belajar matakuliah kimia dasar dengan nilai KKM 70 diketahui bahwa $84 \%$ mahasiwa tuntas belajar. Persentase ketuntasan belajar berdasarkan gaya belajar mata kuliah kimia dasar Mahasiswa Program Studi Ilmu Ternak Fakultas Peternakan Universitas Islam Balitar Semester Ganjil Tahun Akademik 2016-2017 yang disajikan pada Gambar 2 diketahui bahwa ketuntasan belajar berdasarkan gaya belajar secara berurutan adalah kinestetik $100 \%$, auditorial $86 \%$, dan visual $81 \%$. Dari data ini diketahui bahwa mahasiswa dengan gaya belajar kinestetik lebih baik dalam penguasaan materi matakuliah kimia dasar jika dibandingkan dengan mahasiswa dengan gaya belajar auditorial maupun visual.

Gaya belajar kinestetik adalah gaya belajar dengan mengutamakan indera perasaan dan gerakan fisik. Orang dengan gaya belajar ini lebih mudah menangkap pelajaran apabila ia bergerak atau mengambil tindakan. Belajar secara kinestetik berhubungan dengan praktik atau pengalaman belajar secara langsung (Subini, 2012). Jika dilihat dari karakter pembelajaran kimia dasar, adalah matakuliah yang bertujuan untuk memperoleh pengalamana dalam menerapkan metode ilmiah melalui percobaan dan eksperimen, memahami konsep, hukum, dan teori serta saling kaitannya dan penerapannya untuk menyelesaikan masalah dalam kehidupan sehari-hari (Sastrawijaya, 2007). Jika dilihat dari kararter materi pada mata kuliah kimia dasar, maka pembelajaran kimia dasar akan lebih efektif jika menggunakan metode Scientific Aprroach dimana mahasiswa menemukan dan memahami materi dari pengalaman langsung. Dengan menggunakan metode pembelajaran seperti ini, hasilnya akan dimaksimalkan jika diterapkan pada anak/mahasiswa dengan gaya belajar kinestetik dan visual.

Mata kuliah kimia dasar erat kaitannya dengan praktikum untuk mendalami konsep, teori, maupun hukum. Dalam kegiatan ini mahasiswa dituntut untuk lebih aktif dalam menggunakan indra penglihatan, perciuman, dan peraba untuk melakukan pengamatan di laboratorium. Selain itu mahasiswa juga dituntut untuk lebih energik dan kreatif dalam pembelaajaran tidak hanya sekedar berdiam diri mendegarkan penjelasan dosen. Hal ini sesuai dengan hasil penelitian yang menunjukkan bahwa mahasiswa dengan gaya belajar kinestetik semuanya (100\%) tuntas belajar dalam mata kuliah kimia dasar. Mahasiswa dengan gaya belajar visual meskipun hanya $81 \%$ tuntas belajar, namun hasil ini dinilai sudah cukup memuaskan.

\section{PENUTUP}


Devita Sulistiana. 2018. Analisis Gaya Belajar Mahasiswa Dan Hubungannya Dengan Hasil Belajar Kimia Dasar Mahasiswa Program Studi Ilmu Ternak Fakultas Peternakan Universitas Islam Balitar Semester Ganjil Tahun Akademik 2016-2017.

Universitas Islam Balitar.

Konstruktivisme, 10 (1): 84-97

\section{Kesimpulan}

Berdasarkan permasalahan yang diungkapkan dan analisis data, maka pada bagian ini akan disampaikan kesimpulan sebagai berikut:

1. Secara keseluruhan terlihat bahwa gaya belajar auditorial banyak digunakan mahasiswa sebesar $50 \%$, gaya belajar visual sebesar $36 \%$, dan gaya belajar kinestetik sebesar $14 \%$.

2. Mahasiswa dengan gaya belajar kinestetik dapat menguasai mata kuliah kimia dasar dengan persentase ketuntasan 100\%, sementara mahasiswa dengan gaya belajar auditorial $86 \%$, dan visual $81 \%$.

\section{Saran}

Berdasarkan penelitian yang telah dilakukan maka disarankan agar:

1. Bagi dosen, sebaiknya harus memperhatikan gaya belajar masingmasing mahasiswa, sehingga kegiatan belajar mengajarnya tidak monoton, karena dengan mengenali gaya belajar masingmasing mahasiswa tersebut akan belajar lebih giat, maka akan mampu meningkatkan hasil belajar mahasiswa.

2. Bagi mahasiswa, diharapkan mampu mengenali gaya belajar masing karena dengan mengenali gaya belajar tersebut mereka akan dapat mengetahui cara yang sesuai dalam menyerap pelajaran serta membuat belajar itu lebih mudah, efektif dan menyenangkan. Dengan terwujudnya hal tersebut mahasiswa akan mampu meningkatkan hasil belajar mereka.

3. Bagi sekolah, sebaiknya dijadikan sebagai referensi dan bahan pertimbangan dalam merencanakan program sekolah yang berkenaan dengan hasil belajar. Maka sebaliknya dapat dilakukan dengan memberikan motivasi terhadap mahasiswa agar mengenali gaya belajar masingmasing guna meningkatkan hasil belajar yang diinginkan.

4. Bagi peneliti selanjutnya lebih bisa mencari variabel-variabel lain. Sehingga penelitian yang selanjutnya akan bisa lebih dikembangkan lagi dan bisa menjadi lebih baik lagi.

\section{DAFTAR PUSTAKA}

Agustama, Yudha dan Makbul Muksar. 2012. Identifikasi Gaya Belajar Matematika Mahasiswa Kelas VII di SMP Negeri 14 Malang, Jurnal Online Matematika - Universitas Negeri Malang, Volume 1, Nomor 2, Tahun 2012. 
Devita Sulistiana. 2018. Analisis Gaya Belajar Mahasiswa Dan Hubungannya Dengan Hasil Belajar Kimia Dasar Mahasiswa Program Studi Ilmu Ternak Fakultas Peternakan Universitas Islam Balitar Semester Ganjil Tahun Akademik 2016-2017. Universitas Islam Balitar. Konstruktivisme, 10 (1): 84-97

Arikunto, Suharsimi. 2006. Prosedur Penelitian Suatu Pendekatan Praktik, Jakarta: Rineka Cipta Astuti, Endang Sri dan RetnoWidajati. 2010. Bahan Dasar untuk Pelayanan Konseling pada Satuan Pendidikan Menengah - Jilid I, Jakarta: Grasindo.

Aunurrahman. 2009. Belajar dan Pembelajaran. Bandung: Alfabeta. Danim, Sudarwan dan Khairil. 2010. Psikologi Pendidikan (Dalam Perspektif Baru), Bandung: Alfabeta.

Gerung, Nixon J. 2012.Conceptual Teaching and Learni ngStyle (Kajian Konseptual tentang Belajar dan GayaBelajar), Jurnal Uniera, Volume 1, Nomor 1, Februari2012.

Gora, Wirastwan dan Sunarto. 2010. Pakematik: Strategi Pembelajaran Inovatif Berbasis TIK, Jakarta: ElexmediaKomputindo.

Hasbullah. 2009. Dasar-dasar IImu Pendidikan, Jakarta: Raja Grafindo Persada.

Hasan, Iqbal. (2006). Analisis Data Penelitian dengan Statistik, Jakarta: Bumi Aksara.

Harahap, FriskaAdiyantry. 2012. Analisis Gaya Belajar Mahasiswa dan Hubungannya dengan Hasil Belajar Biologi Mahasiswa Kelas XI IPA SMA Negeri 1 Stabat Tahun Pembelajaran 2011/2012. Skripsi, Pendidikan Biologi, Universitas Negeri Medan.

Jihad, Asep. 2009. Evaluasi Pembelajaran. Yogyakarta: Multi Pressindo.

Johnson, Elaine B. 2007. Contextual Teachingand Learni ng: Menjadikan Kegiatan Belajar Mengajar Mengasyikkan dan Bermakna, Bandung: MLC.

Lucy, Bunda. 2009. Mendidik Sesuai dengan Minat \& Bakat Anak (PaintingYour Children's Future), Jakarta: Tangga Pustaka.

Margono. S. 2004. Metodologi Penelitian Pendidikan. Jakarta: Rineka Cipta

Maryam. 2013. Pemanfaatan Lingkungan Sekolah untuk Meningkatkan Hasil Belajar Mahasiswa Kelas X-3 MAN Binjai pada Pelajaran Biologi, Jurnal Penelitian Tindakan Kelas, Volume 2, Nomor 1, Juni 2013.

Nasution, S. 2010. Berbagai Pendekatan dalam Proses Belajar \& Mengajar, Jakarta:Bumi Aksara.

Nurochma, Rofa. 2012. Perbedaan Hasil Belajar dengan Penerapan Strategi Pembelajaran Guidedlnquiry dan Demonstrasi Ditinjau dari Gaya Belajar Mahasiswa Kelas VIII SMP Negeri 1 Jaten tahun Pelajaran 2011/2012. Jurnal Pendidikan Biologi Universitas Sebelas Maret. 
Devita Sulistiana. 2018. Analisis Gaya Belajar Mahasiswa Dan Hubungannya Dengan Hasil Belajar Kimia Dasar Mahasiswa Program Studi Ilmu Ternak Fakultas Peternakan Universitas Islam Balitar Semester Ganjil Tahun Akademik 2016-2017.

Universitas Islam Balitar.

Konstruktivisme, 10 (1): 84-97

Pradipto, Y. Dedy. 2007. Belajar Sejati Vs Kurikulum Nasional, Yogyakarta: Kanisius.

Prashnig, Barbara. 2007. The Power of The LearningStyles: Memacu Anak Melejitkan Prestasi dengan Mengenali Gaya Belajarnya. Jakarta: Kaifa.

Purwanto. 2009. Evaluasi Hasil Belajar. Yogyakarta: Pustaka Setia.

Putri, Asti Widya. 2013. Pengaruh Gaya Belajar Mahasiswa (Visual, Kinestetik, dan Auditorial) pada Mata Pelajaran Mengelola Peralatan Kantor Terhadap Hasil Belajar, Skripsi Universitas Negeri

Surabaya Fakultas Ekonomi Jurusan Pendidikan Ekonomi Prodi Administrasi Perkantoran.

Riduwan, 2009. Pengantar Statistika untuk Penelitian: Pendidikan, Sosia; Komunikasi, Ekonomi, dan Bisnis. Bandung: Alfabeta

Riduwan, 2011. Belajar Mudah Penelitian untuk Dosen- Karyawan dan Peneliti Pemula. Bandung: Alfabeta

Slameto. 2003. Belajar dan Faktor- Faktor yang Mempengaruhinya. Jakarta: Rineka Cipta.

Soedibjo, N. 2008. Perancangan Balanced Skripsi. Jakarta: Universitas Indonesia

Sudjana, 1992. Metode Statistika. Bandung: Tarsito

Sugiyono. 2008. Metodologi Penelitian Pendidikan Pendekatan Kuantitatif, Kualitatif dan $R \& D$, Bandung: Alfabeta

Sukardi. 2008. Metodologi Penelitian Pendidikan. Jakarta: Bumi Aksara

Sukmadinata, N. S. 2008. Metodologi Penelitian Pendidikan. Bandung: Remaja Rosdakarya Uno, Hamzah B. 2006. Teori Motivasi dan Pengukurannya Analisis di Bidang Pendidikan, Jakarta: Bumi Aksara.

Wulandari, Fitria Eka. 2011. Pengembangan Media Pembelajaran Biologi SMP Berbasis Komputer Bahan Kajian Sistem Syaraf dan Sistem Indera pada Manusia, Jurnal Pedagogia, Volume 1, Nomor 1. Desember 2011: 99- 109. 